\title{
Teacher's and Students' Beliefs on English for General Academic Purposes: The Case of Iranian University Students
}

\author{
Masoud Kermani Kojour ${ }^{1} \&$ Javad Kia Heirati ${ }^{2}$ \\ ${ }^{1}$ Department of English Language, Payame Noor University, Rasht Branch, Rasht, Iran \\ ${ }^{2}$ Department of English Language and Literature, University of Mazandaran, Iran \\ Correspondence: Javad Kia Heirati, graduate student of TEFL, University of Mazandaran, Babolsar, Islamic \\ Republic of Iran. Tel: 98-9111-953-157. E-mail: Javad.kiaheirati@yahoo.com
}

\author{
Received: Septemberber 27, 2015 Accepted: November 2, 2015 Online Published: November 5, 2015 \\ doi:10.5539/elt.v8n12p37 \\ URL: http://dx.doi.org/10.5539/elt.v8n12p37
}

\begin{abstract}
This study was framed in the sociocultural theory to look into the evolution of L2 learners' beliefs about the general English course during a term. One hundred ninety-eight male and female university students and their general English course teacher were randomly selected as the participants of the study. Data were gathered through the administration of Horwitz's (1988) BALLI questionnaire. Among the participants, 38 students were invited to take part in semi-structured interview sessions and fill in an open-ended questionnaire at the beginning and end of the term. Descriptive statics were applied to precisely analyze the quantitative data based on the questionnaire. In order to qualitatively analyze the data, the grounded theory methodology was utilized to code the data and find the main categories in line with the research questions of the study. Findings concluded that all the learners changed their simplistic beliefs about the general English course highlighting the attention to grammar and vocabulary. In fact, the teacher believed in teaching strategies to pave the way for the learners to comprehend the text better and apply the strategies while reading. The teacher's meditational activity assisted the learners to evolve their simplistic beliefs and be able to benefit from reading strategies for better comprehension. Awareness-raising activities should be done in terms of teachers' and students' beliefs about EGAP (English for general academic purposes) to equip L2 learners with better educational environments resulting in their enjoyment of the learning process.
\end{abstract}

Keywords: learners' beliefs, belief changes, sociocultural theory, awareness raising

\section{Introduction}

\subsection{Beliefs in Language Learning}

As to the role of beliefs in applied linguistics, many scholars have made their best attempts to uncover the complex nature of beliefs since Pajares (1992) argues that beliefs are "messy constructs" (p. 307), highlighting the complicated nature of beliefs systems. Belief studies have been attentively looked into with the appearance of the cognitive theories of learning, considering beliefs as metacognitve knowledge (Wenden, 1999). In fact, beliefs were found to be stable in nature as Kalaja (1995) highlights the sort of stability belief systems face with respect to the cognitive systems underlying one's mentality. Studies on the role of beliefs have initially been done by Horwitz (1988) who highlighted the significance of beliefs in the language learning process, which may enhance or reduce this process. Horwitz found that some learners paid much attention to the role of vocabulary and grammar, which seems to be simplistic. She suggests that it is better for learners to take a holistic approach toward learning a language. Other studies (e.g. Fazilatfar, Rayati Damavandi, Harsij Sani, \& Kia Heirati, 2014) also took account the beliefs and their changes in the process of language learning, highlighting the significance of beliefs in language learning process. Recent approaches toward belief studies have focused on the application of the sociocultural theory to investigate the dynamic nature of beliefs (see Rayati Damavandi, \& Kia Heirati, 2015) and how they evolve during a period of time as a result of being involved in the context of interaction (see Alanen, 2006; Kalaja \& Barcelos, 2006). As beliefs have been recognized as a key issue in the learning process, the study aimed to take the teacher and learners' beliefs about a general English course at university focusing on English for general academic purposes (EGAP) as a sub-division of English for specific purposes (ESP) and English for academic purposes (EAP). In the following, a brief history of the issue is provided. 


\subsection{What is ESP?}

English for Specific Purposes (ESP) is a branch of English Language Teaching (ELT), which can be divided into two main categories of English for Academic Purposes (EAP) (such as Medicine, Engineering, Theology, etc.) and English for Occupational Purposes (EOP) (such as English for secretaries, technicians, etc.). As to the developments of science and technology and the appearance of many courses (e.g. geography, medicine, engineering, theology, etc.), it makes EAP as a special language in a way that the materials should be compiled in accordance with that course.

According to Robinson (1991), what is considered 'specific' about ESP in a given location in the world may not be considered the same elsewhere. Thus, a clear definition of ESP seems to be rather complex. ESP-related textbooks used for any major and the ability to present and teach them in a classroom demands the teachers' familiarity with issues of that major, whereas such a familiarity cannot be a fair justification for compiling general English textbooks (Ahmadi \& Bajelani, 2012). Therefore, it is necessary for an ESP teacher to be of good proficiency level and also have a sort of familiarity with the presented material.

Others like Hutchinson and Waters (1992) are interested in finding out 'what ESP is not' instead of find the answer to 'what ESP actually is'. In this case, they would say:

“1). ESP is not teaching 'specialized varieties' of English, because using English for a specific purpose does not mean using one special aspect of language.

2). ESP is not teaching a series of words and structures (grammar) to people who need it.

3). ESP, in terms of educational methods, is not different from other teaching methods. Although contents in ESP are pretty different from those of general English, there is no account for difference between educational processes" (p. 18).

So, according to Hutchinson and Waters ESP is something which is not gained as a product, rather than it is a matter of process.

\subsection{Purpose of ESP for Students of Non-English Courses in Universities}

ESP aims at creating a better space for learners who are concerning with English language as an effective major especially in universities in Iran. Students must be informed of the most recent developments in the world by the technologies which are growing fast. Being aware of scientific technologies is not only useful but essential (Ahmadi \& Bajelani, 2012). Most graduate students in Iran are concerned with this problem that how they can be a good English learner who is able to have a hand in all major skills in English. Thus, it is of value for these students to become aware of their perceptions regarding the language and learning needs.

Although the bulk of undergraduate-level English instruction in Iran deals with teaching EAP, it seems to be of a limited scope and has overlooked the principles underlying course design, which should be taken into account as an on-going process to suit students' interests and needs (Sifakis, 2003). It seems that in foreign language contexts such as Iran, most students, especially graduate ESP students, are not aware of their language and learning needs. Understanding what sort of perceptions they have regarding the course they are passing and what kinds of skills they are going to gain as a result of one semester passing a special English course gives them a sort of awareness regarding the major skills in English and what actually they expect their ESP teachers to fulfill their requirements regarding their needs. Thus, it gives an insight to our ESP teachers to become familiar with learner preferences and this leads to better understanding of the learners' needs and consequently to effective teaching.

As to the importance of the belief systems and the fact that they play an important role in the language learning process, and the effectiveness of raising awareness of EGAP teachers and their students in terms of their beliefs about general English course at universities, it is of value to look into the learners' beliefs about general English course as well as their teacher to see whether they are aware of EGAP, and if learners beliefs are found to be simplistic, to what extent the teacher can assist the students to evolve their simplistic beliefs at the end of term as a result of taking this course during one term at university. In fact, the present study replicates the research carried out by Fazilatfar et al (2014) in that the current research qualitatively probes the learners' evolution of their beliefs about EGAP at the end of the term.

\section{Research Questions}

The study seeks answers for the following questions:

1). What are the university students' beliefs about the general English course at the beginning of the term? 
2). What are the teacher's beliefs about teaching the general English course at university?

3). Do learners' beliefs about the general English course evolve at the end of the term?

\section{Methodology}

\subsection{Participants}

To gather the data, 198 EFL (English as a Foreign Language) students, majoring in Persian Literature, Russian Translation, Educational Sciences, and Commercial Management, were selected as potential candidates of the present study. They were kindly requested to fill in the questionnaire and take part in an interview session and fill in the open-ended questionnaire. It should be noted that 38 students were randomly selected to take part in the interview and fill in the questionnaire to interpretively analyze their belief systems. The students' teacher was invited to take part as an interviewee. It is of value to note that all the participants were in their first year of the university.

\subsection{Instruments}

The survey instrument consisted of 34 items from the 'Beliefs About Language Learning Inventory (BALLI)' designed by Horwitz (1988). The BALLI is a widely used instrument (e.g. Kern, 1995) to probe the learners' beliefs about language learning in five areas including foreign language aptitude, the difficulty of language learning, the nature of language learning, learning and communication strategies, and Motivations and expectations. Students were given the Persian version of BALLI with some modifications to fit the context of Iran and were asked to read each item, and to respond using a five-point scale, ranging from 1 (strongly agree) to 5 (strongly disagree). The items asking for the difficulty of the English language learning (item 4) ranged from 1 (very difficult) to 5 (very easy), and the one for the item asking about how long it takes to speak English (item 15) ranged from 1 (less than one hour) to 5 (you can't learn a language in one hour per day). This questionnaire was administered at the beginning and end of the term.

To qualitatively collect the data regarding learners' and teachers' beliefs about general English course, open-ended questionnaire and semi-structured interviews were applied to gather the desirable data. Regarding the benefit of open-ended questionnaire, Mackay and Gass (2005) put forward that it is really beneficial for researchers when they want to create a relaxed atmosphere to freely express their opinion on the matter. Regarding semi-structured interview, Dornyei (2007) points to the effectiveness of this type of interview in that it paves the way for the researcher to elaborate on the issue and collect necessary data concerning the purpose of the study while no pressure seems to be on the participants. Hence, the present research applied open-ended questionnaire and semi-structured interview to look into the learners and teachers' beliefs about EGAP, and how the learners' beliefs evolve once they pass the general English course.

\subsection{Procedure}

The university students were requested to fill in the BALLI questionnaire at the beginning and end of the term. The participants were also invited to take part in interview session and fill in the open-ended questionnaire to find out their beliefs about EGAP at the beginning and end of term. They were free to talk about everything, and they were also asked some general questions with respect to the course they were to pass. The participants took part in 10 sessions of the general English course. The teacher was cordially invited to the interview before the term to look in to his beliefs about general English course. It should be noted that the general English course is taught in the form of reading comprehension skill at universities in Iran aiming to help the learners overcome their comprehension problems. The strategy instruction was based on the textbook with the purpose of arming the students with common reading strategies, such as predicting, skimming, scanning, and guessing meaning from the context.

\subsection{Data Analysis}

For quantitative data analysis, the learners' responses to the items were analyzed both descriptively and inferentially. At first, to have a better view of the distribution of the responses, the BALLI item were turned into three categories of agree (A), neutral (N), and disagree (D) and also difficult, neutral, and easy (for item 4). Then the frequency of the responses for both time 1 (before the semester) and time 2 (after the semester) was calculated and presented in tables.

As the present study also benefitted from qualitative data collection methodology, data analysis can be done qualitatively with the application of grounded theory methodology (Glaser \& Straus, 1967), which is a kind of text analysis and in favor of coding the data to reach final categorization based on the purpose of the study. Dornyei (2007) supports the application of grounded theory in qualitative analysis because researchers can 
interpretively go through the text and categorize the coded data emerged with respect to the research questions underlying the research. Since the study used semi-structured interview and open-ended questionnaire to collect the required data, the main codes were extracted to answer the questions of the study. Each of the main codes consists of sub-codes to thematically analyze the data. Furthermore, partial transcriptions of interview were provided to highlight the sort of belief the participants may hold about EGAP.

\section{Results}

The purpose of the study was to look into the learners' beliefs about general English course at the beginning of the term and see how the learners might evolve their beliefs when they finished the course. The study also focused on the teacher's beliefs in terms of teaching general English course. It should be noted that general English course is taught with the focus on reading comprehension in Iranian universities. Hence, analysis of the research questions is brought in the following to qualitatively report the results.

\subsection{First Research Question}

As to the first research question, it was aimed to figure out the learners' awareness of the course they were to pass during the term. As the study applied both quantitative and qualitative methodology to analyze the data, first, the results of the BALLI questionnaire at the beginning and end of the term are provided, then, the findings concerning grounded theory methodology are presented.

\subsubsection{Quantitative Analysis of BALLI}

Foreign Language Aptitude: as to the participants' responses to the questionnaire, it was found that they might have positive attitude toward people's potential to learn a foreign language. As Table 1 shows, a large number of the participants concurred that everyone can learn a foreign language $(86.9 \%)$ and children have a special aptitude in learning a foreign language (88.9\%). The majority of them $(72.7 \%)$ also believed that some people are born with a special ability to learn a foreign language. Although they held positive beliefs in terms of people's special ability for learning a foreign language, less than half of them $(41.9 \%)$ stated that Iranians are successful in learning English.

Table 1. Language learning aptitude from times 1 and 2

\begin{tabular}{ccccc}
\hline Items & $A$ & $N$ & $D$ & Time \\
\hline 1 & 88.9 & 8.6 & 2.5 & 1 \\
& 86.9 & 9.6 & 3.5 & 2 \\
2 & 72.7 & 15.2 & 12.1 & 1 \\
& 78.3 & 13.6 & 8.1 & 1 \\
6 & 41.9 & 33.3 & 24.7 & 2 \\
& 42.9 & 34.3 & 27.7 & 1 \\
10 & 55.1 & 25.3 & 19.7 & 2 \\
& 59.9 & 27.4 & 12.7 & 1 \\
\multirow{2}{*}{11} & 5.6 & 22.2 & 72.2 & 2 \\
& 11.1 & 28.8 & 60.1 & 1 \\
\multirow{2}{*}{16} & 40.9 & 39.9 & 19.2 & 1 \\
& 39.9 & 40.4 & 19.7 & 2 \\
& 26.8 & 44.4 & 28.8 & 1 \\
& 30.8 & 49.5 & 19.7 & 2 \\
& 59.1 & 28.3 & 12.6 & 1 \\
& 55.1 & 31.8 & 13.1 & 2 \\
\hline
\end{tabular}

To inferentially measure the responses, a chi-square goodness of fit was conducted and showed a significant difference in the proportion of participants' responses for all the items related to language learning aptitude (item 
$1: \chi^{2}(1, \mathrm{n}=198)=276.091, p=.00<.05 ;$ item $2: \chi^{2}(1, \mathrm{n}=198)=138.545, p=.00<.05 ;$ item $6: \chi^{2}(1, \mathrm{n}=198)$ $=8.758, p=.01<.05 ;$ item 10: $\chi^{2}(1, \mathrm{n}=198)=42.939, p=.00<.05 ;$ item $11: \chi^{2}(1, \mathrm{n}=198)=143, p=.00$ $<.05$; item 16: $\chi^{2}(1, \mathrm{n}=198)=17.848, p=.00<.05$; item 19: $\chi^{2}(1, \mathrm{n}=198)=11.121, p=.00<.05 ;$ item $30: \chi^{2}$ $(1, \mathrm{n}=198)=66.394, p=.00<.05 ;$ item 33: $\left.\chi^{2}(1, \mathrm{n}=198)=256.455, p=.00<.05\right)$.

As to their beliefs about language aptitude, the changes in the percentages gained in time 1 and 2 were rather small. As can be seen in Table 1 above, the changes in all the items related to language aptitude were up to 6 percents.

The Difficulty of Language Learning: As Table 2 shows, over half of the participants took the position that finally they would manage to learn English (58\%) and they were able to learn English in less than two years $(57.6 \%)$, while 16.2 percent agreed that more than five years is required for learning English. Some (13. 6\%) thought that they would not learn English. Furthermore, they also stated that some languages are easier to learn than others. Most of them (75.8\%) agreed with the case of learning some languages, and English seems to be one of them. A very small percentage (26.8\%) concurred that English is a difficult language. About one third of the participants $(36.9 \%)$ agreed with the statement that it is easier to speak than to understand a foreign language. Also, almost half of the participants (54.5\%) agreed with the ease to read and write.

Table 2. Difficulty of language learning from times 1 and 2

\begin{tabular}{|c|c|c|c|c|}
\hline Items & $A$ & $N$ & $D$ & Time \\
\hline \multirow[t]{2}{*}{3} & 75.8 & 16.2 & 8.1 & 1 \\
\hline & 81.8 & 14.6 & 3.5 & 2 \\
\hline \multirow[t]{2}{*}{4} & 26.8 & 45.5 & 27.8 & 1 \\
\hline & 54.5 & 40.4 & 5.1 & 2 \\
\hline \multirow[t]{2}{*}{5} & 58.1 & 28.3 & 13.6 & 1 \\
\hline & 57.1 & 29.3 & 13.6 & 2 \\
\hline \multirow[t]{2}{*}{15} & 57.6 & 26.3 & 16.2 & 1 \\
\hline & 59.1 & 25.3 & 15.7 & 2 \\
\hline \multirow[t]{2}{*}{25} & 36.9 & 38.9 & 24.2 & 1 \\
\hline & 38.4 & 35.9 & 25.8 & 2 \\
\hline \multirow[t]{2}{*}{34} & 54.5 & 29.3 & 16.2 & 1 \\
\hline & 54 & 32.3 & 13.6 & 2 \\
\hline
\end{tabular}

The chi-square of fit was carried out and showed a significant difference in the proportion of the participants' responses related to language difficulty $\left(\right.$ item $3: \chi^{2}(1, \mathrm{n}=198)=162.303, p=.00<.05$; item $4: \chi^{2}(1, \mathrm{n}=198)=$ $13.121, p=.00<.05 ;$ item 5: $\chi^{2}(1, \mathrm{n}=198)=60.939, p=.00<.05 ;$ item $15: \chi^{2}(1, \mathrm{n}=198)=55.394, p=.00$ $<.05$; item 25: $\chi^{2}(1, \mathrm{n}=198)=7.485, p=.02<.05$; item $\left.34: \chi^{2}(1, \mathrm{n}=198)=45.212, p=.00<.05\right)$.

The percentages in the items about language difficulty showed that except for item 4 the change was so small that the participants' views, to a large extent, did not change in this regard. As to item 4, which is related to the difficulty of English, after passing the semester the number of participants doubled from 26.8 in time 1 to 54.5 in time 2. Passing a reading course at university seems to have made them believe that learning English is difficult.

The Nature of Language Learning: Table 3 indicates the percentage of the participants' responses regarding the nature of language learning. The majority of the participants $(85.9 \%)$ held the belief that learning a foreign language is mostly dependent on a lot of new vocabulary words, whereas they did not take into account the role of grammar rules $(31.8 \%)$. Very few of them $(2.5 \%)$ agreed that learning a lot of new vocabularies was not the most significant part of learning English. 
Table 3. The nature of language learning from times 1 and 2

\begin{tabular}{lllll}
\hline Items & $A$ & $N$ & $D$ & Time \\
\hline 8 & 43.9 & 35.9 & 34.8 & 1 \\
& 48.9 & 20.2 & 15.7 & 2 \\
12 & 67.7 & 17.7 & 14.6 & 1 \\
& 70.7 & 23.2 & 6.1 & 2 \\
& 85.9 & 11.6 & 2.5 & 1 \\
23 & 79.8 & 14.6 & 5.6 & 2 \\
& 31.8 & 30.8 & 37.4 & 1 \\
27 & 21.7 & 40.7 & 37.9 & 2 \\
& 64.1 & 26.8 & 9.1 & 1 \\
& 65.7 & 28.8 & 5.6 & 2 \\
& 56.6 & 32.8 & 10.6 & 1 \\
\hline
\end{tabular}

Not many participants $(43.9 \%)$ were in favor of getting to know the second language culture. Moreover, over half of the participants $(64.1 \%)$ confirmed that learning English seems to be rather different from other university subjects. Similarly, most learners thought that learning English in an English-speaking country could be considered as the chance to best meet the requirements of the learners' language needs (67.7\%). In addition, most of the participants $(56.6 \%)$ believed that knowing how to translate from their L1 to L2 was an important factor in language learning.

As to the quantitative analysis, the result of chi-square goodness of fit revealed a significant difference among the alternatives for all the items except for item 23 as the frequency of the responses was somehow equally distributed for this item (see Table 3) (item 8: $\chi^{2}(1, \mathrm{n}=198)=17.303, p=.00<.05$; item 12: $\chi^{2}(1, \mathrm{n}=198)=$ 105.364, $p=.00<.05$; item 17: $\chi^{2}(1, \mathrm{n}=198)=248.273, p=.00<.05$; item 23: $\chi^{2}(1, \mathrm{n}=198)=1.485, p$ $=.47>.05$; item 27: $\chi^{2}(1, \mathrm{n}=198)=93.848, p=.00<.05$; item 28: $\left.\chi^{2}(1, \mathrm{n}=198)=62.758, p=.00<.05\right)$.

It was also found that learners' belief regarding the nature of language learning did not face any significant changes (See Table 3). Similar to the changes in the previous categories, no big differences can be seen here. The changes were up to 4 percent except for item 23 in which still very few participants, about 10 percent, changed their beliefs about grammar and highlighted it as the most important part in learning English.

Learning and Communication Strategies: the learners' questionnaire shows that a vast majority of the participants strongly recognized the role of practice and repetition (98\%) and practice with audio and video devices (81.8\%). Interestingly, no one denied the role of practice and repetition in learning English (Table 4). Additionally, the data highlighted the importance of speaking English for Iranians (56.6\%). In the same vein, most of the participants (66.2\%) were interested in speaking with native speakers of English. A majority of the participants were interested in speaking with a perfect accent $(80.3 \%)$ and guessing the meaning of unknown words $(80.3 \%)$. However, a very small percentage of them (26.8\%) believed that correct speaking of English seems to be practical although almost half of them (47\%) had a different opinion. 
Table 4. Learning and communication strategies from times 1 and 2

\begin{tabular}{|c|c|c|c|c|}
\hline Items & $A$ & $N$ & $D$ & Time \\
\hline \multirow[t]{2}{*}{7} & 80.3 & 13.1 & 6.6 & 1 \\
\hline & 72.2 & 19.2 & 8.6 & 2 \\
\hline \multirow[t]{2}{*}{9} & 26.8 & 26.3 & 47 & 1 \\
\hline & 20.7 & 30.3 & 49 & 2 \\
\hline \multirow[t]{2}{*}{13} & 66.2 & 27.3 & 6.6 & 1 \\
\hline & 68.2 & 24.7 & 7.1 & 2 \\
\hline \multirow[t]{2}{*}{14} & 80.3 & 15.7 & 4 & 1 \\
\hline & 81.3 & 15.7 & 3 & 2 \\
\hline \multirow[t]{2}{*}{18} & 98 & 2 & 0 & 1 \\
\hline & 89.4 & 8.1 & 2.5 & 2 \\
\hline \multirow[t]{2}{*}{21} & 36.9 & 27.8 & 35.4 & 1 \\
\hline & 32.3 & 39.4 & 28.3 & 2 \\
\hline \multirow[t]{2}{*}{22} & 39.9 & 23.2 & 36.9 & 1 \\
\hline & 35.4 & 31.8 & 32.8 & 2 \\
\hline \multirow[t]{2}{*}{26} & 81.8 & 15.7 & 2.5 & 1 \\
\hline & 74.2 & 22.2 & 3.5 & 2 \\
\hline
\end{tabular}

To measure the learners' responses, a chi-square goodness of fit was carried out and there was found a significant difference in the participants' choices for all the items except for item 21 since the responses were relatively equally distributed (see Table 4) (item 7: $\chi^{2}(1, \mathrm{n}=198)=197.848, p=.00<.05$; item 9: $\chi^{2}(1, \mathrm{n}=198)=16.576$, $p=.00<.05$; item 13: $\chi^{2}(1, \mathrm{n}=198)=108.758, p=.00<.05 ;$ item $14: \chi^{2}(1, \mathrm{n}=198)=200.576, p=.00>.05$; item 18: $\chi^{2}(1, \mathrm{n}=198)=182.323, p=.00<.05 ;$ item $21: \chi^{2}(1, \mathrm{n}=198)=2.818, p=.24>.05 ;$ item $22: \chi^{2}(1, \mathrm{n}=$ $198)=9.364, p=.00<.05$; item $\left.26: \chi^{2}(1, \mathrm{n}=198)=214.576, p=.00<.05\right)$.

It should be noted that, as Table 4 illustrates, no significant changes have been observed in the proportion of the participants' responses. The changes in the percentage of the two times were rather small, up to 6 percent.

Motivations and Expectations: concerning the learners' responses to the items of motivation in learning the language, it was found that a vast majority of the participants were positive toward two statements of items 29 $(89.4 \%)$ and $31(92.9 \%)$ in that they can get more job opportunities and they want to speak English very well. Iranians' desire to speak English was held by more than half of the learners $(56.6 \%)$, and the belief that it is important to learn to speak English for social communication with people $(54 \%)$, and that they like to have native speakers as their friends $(60.1 \%)$ (Table 5).

Table 5. Motivations and expectations from times 1 and 2

\begin{tabular}{lllll}
\hline Items & $A$ & $N$ & $D$ & Time \\
\hline 20 & 56.6 & 32.3 & 11.1 & 1 \\
& 55.1 & 33.8 & 11.1 & 2 \\
24 & 54 & 27.3 & 13.7 & 1 \\
29 & 50 & 28.3 & 21.7 & 2 \\
31 & 89.4 & 8.5 & 2 & 2 \\
& 83.3 & 11.6 & 5.1 & 1 \\
32 & 92.9 & 6.1 & 1 & 2 \\
& 86.9 & 10.6 & 2.5 & 1 \\
\end{tabular}


The result of the chi-square goodness of fit highlighted significant differences in the learners' responses regarding their motivations and expectation (item 20: $\chi^{2}(1, \mathrm{n}=198)=61.455, p=.00<.05$; item $24: \chi^{2}(1, \mathrm{n}=$ $198)=40.394, p=.00<.05$; item 29: $\chi^{2}(1, \mathrm{n}=198)=281.303, p=.00<.05$; item $32: \chi^{2}(1, \mathrm{n}=198)=45.364$, $p=.00<.05)$.

Finally, no significant difference was obseved among the proportions of the participants' responses in the two times regarding motivations and expectations about learning English. That is, similar to the previous categories, the changes are up 6 percent. In the following, qualitative findings are provided.

\subsubsection{Qualitative Analysis}

Regarding the grounded theory methodology, the main category based on the research question and thematic representation of the learners' responses to the open-ended questionnaire and semi-structured interview included 'the learners' beliefs about general English course at the beginning of the term' as well as a sub-categorization i.e. 'importance of vocabulary and grammar', which are explained in the following.

As to the learners' beliefs about general English course at the beginning of the term, the importance of vocabulary and grammar has been highlighted by the participants since the majority of the participants $(n=35)$ highlighted the importance of learning vocabularies and grammar of English in the course they were supposed to take during the term and put much more value on these constituents in that they could help them to learn English faster. Although they seemed to point to some language components, they appeared not to be aware of strategy instruction in the general English course since it focuses on reading comprehension, requiring teaching strategies to facilitate the reading comprehension process. As an example, one of the participants' interview extract is brought:

\section{Extract 1 .}

"It is better to concentrate on grammar. I am very weak in structure and with this course, I guess I can learn a lot about language forms leading to better learning...I expect our teacher to teach us grammar and nothing else."

The above extract clearly shows the simplicity of the participant's beliefs in terms of learning a language, and he might not be aware of the course he was to take and what he was expected to do in the classroom. Moreover, his lack of awareness in case of reading strategies were also sensed in his extract revealing teacher's demanding job to fairly deal with these beliefs at the beginning of the term and bring about positive and realistic beliefs in their mentality toward EGAP. Vocabulary was another constituent, which was mostly attended by the participants. The extract below shows the participant's emphasis on the role of vocabulary in the general English course.

\section{Extract 2.}

"I hope that we learn many vocabularies during this term; they can help us to speak in English and enjoy learning. I do not know a lot of vocabulary, so I want our teacher to help us learn a lot of vocabularies."

Similar to the first extract, the second one showed that she was not aware of the general English course and inattentively focused on the role of vocabulary in learning a language. Furthermore, the participant seemed not to be aware of reading comprehension course because she did not point to the role of reading strategies in her questionnaire and interview.

To conclude, it seems that the participants of the study held simplistic beliefs about general English course they were going to take at the beginning of the term regardless of what is actually required for general English course aiming to teach reading comprehension. Here, it is of value to go for their teacher's point of view regarding teaching general English course to investigate whether he was aware of teaching reading comprehension or unconsciously concentrating on the role of vocabulary and grammar as highlighted in the participants' data.

\subsection{Second Research Question}

To answer the second research question, i.e. what are the teacher's beliefs about teaching the general English course at university, grounded theory approach was applied to qualitatively go for analyzing and coding the interview data with respect to the purpose of the research. Regarding the teacher's interview, the main category of his interview is 'learners should be armed with strategies', highlighting his awareness and persistence in teaching reading strategies to facilitate the reading comprehension and make the learners aware of the general English course they were to take.

\subsubsection{Teacher's Beliefs about General English Course}

Learners Should Be Armed with Strategies: the teacher's interview at the beginning of the term obviously 
indicated that he held realistic beliefs about general English course in terms of strategy instruction and making the learners familiar with common reading comprehension strategies to enhance their awareness regarding their beliefs about EGAP. The teacher seemed to be worried about the participants' background since he believed that most of the learners concentrated on vocabulary and grammar in their high schools regardless of the aim of the reading comprehension process, and this causes difficulties for us to pave the way for the university students to learn strategies underlying reading comprehension. To highlight the teacher's logical beliefs about general English course, it is better to take his extract into consideration as in the following:

\section{Extract 3 .}

"I believe that learners should be taught reading strategies, such as skimming, scanning, guessing meaning, and etc. although it is difficult to change their high school beliefs, which mainly focused on the role of grammar and vocabulary similar to Grammar Translation Method."

Although the teacher insisted on the role of teaching reading strategies to increase the learners' reading comprehension skills, he stared to criticize high school teachers, who seemed to follow traditional teaching methodologies aiming at arming the students with language forms and words. Regarding these pre-university beliefs, it seems to some extent difficult to change their apparent unrealistic beliefs concerning general English course as their teacher pointed out in his interview extract that it is really demanding to bring about evolution in the learners' simplistic beliefs about the course. After looking into the teacher's beliefs about EGAP, it is better to take the teacher's performance into consideration and investigate his success in changing the learners' simplistic and unrealistic beliefs by answering to the third research question.

\subsection{Third Research Question}

To what extent learners' beliefs about general English course have been evolved at the end of the term was the third research question of the study, aiming to investigate the effectiveness of the general English course and the teacher on the participants' simplistic beliefs about the course. In fact, the purpose was to raise students' awareness in terms of reading comprehension strategies and generally English for general academic purpose at universities. As to the participants' beliefs in the interview sessions and open-ended questionnaire, all of them $(n=38)$ held positive beliefs about the course, and they were grateful to their teachers in that he created an atmosphere to enable the learners to learn and apply the strategies while reading the text. To interpretively analyze the data, grounded theory methodology was applied to code the learners' questionnaire and interview. The main category was 'strategy instruction is helpful', which was frequently implied in the data.

\subsubsection{The Evolution of Students' Beliefs about General English Course}

Strategy Instruction Is Helpful: As already mentioned in the previous section, all the participants changed their simplistic beliefs about the course and pointed out the effectiveness of the strategies taught in the class paving the way for better understanding of the text without focusing too much on the grammar and vocabulary as they were mostly focused on at the beginning of the term. In fact, it seems that the general English course led to evolution of the learners' beliefs at the end of the term in that they were happy to apply the strategies while reading a text as it was highlighted in one of the interview extracts:

\section{Extract 4.}

"I am grateful to my teacher. He taught us how to predict before reading the text...I did it and was happy to guess the topic and it helped me to understand the general meaning of the text."

The friendly atmosphere created by the teacher seemed to be effective in fact almost all the learners were thankful to their teacher because he raised their awareness in terms of reading comprehension and general English course, and how they should apply the reading strategies to easily read and comprehend the text without wasting their time for grammar and vocabularies leading to their misunderstanding and getting tired of reading as it was pointed out in the following extract:

\section{Extract 5.}

"In the past, when I wanted to start reading a text, I looked up the words in the dictionary and translated the lines. I understood nothing and got tired. But in this term, my views have been changed; I could read the without getting worried about the meaning of vocabularies or grammar. Strategies were really helpful."

It seems that the general English course was successful in changing the learners' simplistic beliefs at the beginning of the term, leading to their high level of self-confidence when facing a text to read and comprehend it. The teacher's role should not be ignored in that he created an interactive atmosphere in order to make the learners aware of the general English course and how they can deal with reading comprehension task with the 
application of taught strategies.

\section{Discussion}

The present study investigated the university students' beliefs about general English at the beginning of the term and concluded that almost all the learners held simplistic beliefs about this course in that they paid much more attention on the role of vocabulary and grammar, which seems to spring from their high school period focusing on translation and language forms as it was highlighted in the learners' questionnaires and interview when the learners compared their high school classes with university. As socicultural theory was applied to go through the theoretical findings of the study, it can be in line with Alanen's (2006) claim that beliefs are considered as meditational means aiming to be facilitative in the language learning process. In fact, beliefs seem to be adopted as a tool to regulate the process of language learning through mediation (Lantolf \& Throne, 2006). Teacher's beliefs were also significant in that it was the teacher that armed the students with strategy instruction, as he believed in their application during the term, and brought about changes in the learners' beliefs about EGAP. To theoretically challenge the findings, the role of mediation is highlighted because the teacher seemed to take the role of mediator and the strategy instruction learners have underwent during the term might be the mediation itself since both the teacher and the strategy instruction were the main factors in the evolution of the learners' beliefs as all the participants of the study evolved their simplistic beliefs about general English course while thanking the teacher and satisfying with the term passed. Hence, the evolution of the learners' beliefs can be in alignment in Allen's (1996) and Yang and Kim's (2011) qualitative research to go for the role of sociocultural framework to interpretively investigate the belief systems.

\section{Conclusion}

The study was an attempt to raise university students' awareness in terms of their beliefs about general English course. It was found that the majority of the participants were not aware of the EGAP and they were unconsciously focused on the role of language forms and vocabularies, while all of them changed their unrealistic beliefs as a result of receiving the strategy instruction helping them to read and comprehend a text easier and apply the strategies to get mastery over the content.

If teachers be aware of their students' beliefs, it can be challenging for teachers to seek methods to assist the learners to improve their beliefs and enjoy the learning process. Teachers' belief about general English course is of importance since there might be some teachers who would like to focus on grammar and translation regardless of teaching reading strategies. Hence, there seems to be a need to raise both teachers' and learners' beliefs. Teachers can engage in teacher education program for better teaching to upgrade their knowledge of language, and finally they are learners who can benefit from their teachers and enjoy the learning.

\section{References}

Ahmadi, A., \& Bajelani, M. (2012). Barriers to English for specific purposes learning among Iranian University $\begin{array}{lllll}\text { students. Procedia-Social and } & \text { Behavioral }\end{array}$ http://dx.doi.org/10.1016/j.sbspro.2012.06.736

Allen, L. (1996). The evolution of a learner's beliefs about language learning. Carleton Papers in Applied Language Studies, 13, 67-80.

Alanen, R. (2006). A sociocultural approach to young language learners' beliefs about language learning. In P. Kalaja, \& A. M. F. Barcelos (Eds.), Beliefs about SLA: New research approaches (pp. 55-86). Netherlands: Kluwer.

Dornyei, Z. (2007). Research methods in applied linguistics. Oxford: Oxford university press.

Fazilatfar, M. A., Rayati Damavandi, R., Harsij Sani, R., \& Kia Heirati, J. (2014). Learners' belief changes about language learning. International Journal of English Language Education, 3(1), 1-19. http://dx.doi.org/10.5296/ijele.v3i1.6654

Glaser, B. G., \& Strauss. A. (1967). The discovery of grounded theory: Strategies for qualitative research. Chicago: Aldine.

Horwitz, E. (1988). The beliefs about language learning of beginning university foreign language students. Modern Language Journal, 72(3), 283-294. http://dx.doi.org/10.1111/j.1540-4781.1988.tb04190.x

Hutchinson, T., \& Waters, A. (1992). English for Specific Purposes: A Learning centered approach. Cambridge: Cambridge University Press.

Kalaja, P. (1995). Student beliefs (or metacognitive knowledge) about SLA reconsidered. International Journal 
of Applied Linguistics, 5(2), 191-204. http://dx.doi.org/10.1111/j.1473-4192.1995.tb00080.x

Kalaja, P., \& Barcelos, A. M. F. (Eds.) (2006). Beliefs about SLA: New research approaches. Dordrecht: Kluwer Academic Press.

Lantolf, J. P. \& Thorne, S. L. (2006). Sociocultural theory and the genesis of second language development. Oxford: Oxford University Press.

Mackey, A., \& Gass, S. (2005). Second language research, methodology and design. Mahwah, N.J.: Lawrence Erlbaum.

Mazdayasna, G., \& Tharirian, M. H. (2008). Developing a profile of the ESP needs of Iranian students: The case of students of nursing and midwifery. Journal of English for Academic Purposes, 7, 277-289. http://dx.doi.org/10.1016/j.jeap.2008.10.008

Pajares, M. F. (1992). Teacher's beliefs and educational research: Cleaning up a messy construct. Review of Educational research, 62(3), 307-322. http://dx.doi.org/10.3102/00346543062003307

Rayati Damavandi, R., \& Kia Heirati, J. (2015). Investigating change in Iranian EAP learners' beliefs about reading. European Online Journal of Natural and Social Sciences, 4(2), 380-391.

Robinson, P. (1991). ESP today: A practitioner's guide. London: Prentice Hall.

Sifakis, N. C. (2003). Applying the adult education framework to ESP curriculum development: an integrative model. English for Specific Purposes, 22, 195-211. http://dx.doi.org/10.1016/S0889-4906(02)00008-X

Wenden, A. (1999). An introduction to metacognitive knowledge and beliefs in language learning: Beyond the basics. System, 27(4), 435-441. http://dx.doi.org/10.1016/S0346-251X(99)00043-3

Yang, J-S., \& Kim, T-Y. (2011). Sociocultural analysis of second language learner beliefs: A qualitative case study of two study-abroad ESL learners. System, 39(3), 325-334. http://dx.doi.org/10.1016/j.system.2011.07.005

\section{Copyrights}

Copyright for this article is retained by the author(s), with first publication rights granted to the journal.

This is an open-access article distributed under the terms and conditions of the Creative Commons Attribution license (http://creativecommons.org/licenses/by/3.0/). 